\title{
4 \\ Enlightenment Science of Mineral Springs
}

Reforming elites in Enlightenment Mexico City did what they could to clean up the disorder they perceived around them. Policing was their response-the rational management of populations and resources to ensure that both prospered. Studies were carried out to provide information useful for management of the varied castes and classes in the urban center, and for channeling waters more efficiently through infrastructures to private buildings and public fountains. The objects of reform were complex systems that melded resources, infrastructures, and human bodies, ideas, and practices; washing and bathing in particular were subject to scrutiny as cleanliness came to the fore as a pillar of public health and social order. Partly because of this complexity, the policing of waters and baths was haphazardly and selectively enacted.

The promise of bathing was not only moral and physical purity, however. For millennia waters were considered regenerative, therapeutic, and medicinal, and it is hard to overestimate the importance waters held for ideas about health in the ages before antibiotics and surgery. Waters were thought to both cure illnesses and prevent them. There were many categories of waters, each defined by a characteristic: salty, iron, soda, hot, warm, etc. Certain kinds of waters balanced the body's humors in certain ways; others were prescribed for skin problems, venereal disease, kidney stones, even madness. Waters were applied in an empirical and experimental way, based in the traditions passed down by healers and from the texts of antiquity.

In this chapter I continue the discussion of enlightened bathing by turning to the ways that the diversity of Mexico's mineral spring waters were studied, valued, and used during the late eighteenth and early nineteenth centuries. This is a 
story of the growth of scientific knowledge about chemistry, medicine, and related topics such as botany and human physiology, and the importance of springs in the development and application of this knowledge. Historians have shown that northern European mineral and hot springs were especially important sites for growth of science and medicine in the modern period, and this is also true for New Spain, what is today Mexico. A look at the colonial realm of the Americas, however, reveals social dimensions of water cultures that are not commonly portrayed in the literature concerning European hot springs, specifically issues of race, class, access, and power.

There is also something to be learned from American mineral springs about the particular development of science in those longitudes. Colonial science during the Enlightenment grappled with reconciling universal humanism and a search for the exotic and incommensurable. In other words, hot springs and the humans who used them (like plants, animals, and the rest of the natural world) were seen to fit into global classificatory schemes, but inherited European notions that the Americas were fundamentally different lingered. Expeditions were mounted to identify this American exceptionalism and incorporate it into the expanding classification systems of modern science. Scientists traveled to the far corners of New Spain in search of hot springs and measured their temperature, smell, taste, color, density, and chemical composition. These springs were usually already somewhat developed by local users, and local bathing and drinking customs were also chronicled by scientists interested in the medical applications of the waters and the possibility of developing them into spas like those that were become increasingly fashionable across Europe.

A close look at the Enlightenment science of waters reveals a key ontological difference from today's scientific understanding of them. Waters acted; they were medicinal, with qualities described at the time as "virtues." Most people now think of water as an inert, uniform liquid that is controlled and used by people to grow food or flowers and wash dishes, cars, or bodies. Scientists today largely share those ideas, although they recognize that the water molecule is polar, and thus can dissolve many substances, and that as a liquid it can erode solids. In the eighteenth century, however, different waters were seen to have other kinds of effects, and to have them on human bodies. Long before the recent appreciation for "vibrant matter" and nonhuman "actants" in anthropology, Enlightenment science strove to understand the powers of water, and how it formed assemblages with bodies and cultures that came together in human health. ${ }^{1}$

\section{THE VIRTUES OF WATERS}

From the early days of the colony until the Independence struggles, the Crown periodically carried out surveys and censuses of its territories and populations, both in Iberia and the Americas, for use in writing descriptive geographies called 
Relaciones Geográficas. ${ }^{2}$ A review of these surveys provides an overview of how, as the centuries progressed, the topic of mineral waters grew in importance, and also how the cause for that interest changed. At first mineral springs were important as sources of sodium chloride-table salt. Throughout Mesoamerica mineral waters were used for the production of salt, a crucial complement to the largely vegetable-based, sodium-scarce indigenous diet. Ixtapan de la Sal, a hot spring town in today's Mexico State, was famed in the Aztec empire as the source of clean, white salt that circulated as a tribute good. Tequesquite, a naturally occurring combination of sodium chloride and sodium bicarbonate that forms as encrustations on the soil, was also crucial for the diet and economy, and was used in its natural form for cooking and also processed to create sodium chloride. Inhabitants of the Valley of Mexico continued to produce salt from encrustations on the shores of Lake Texcoco until the early twentieth century. ${ }^{3}$ Salt was used for industry as well, such as the curing of meat and, after the arrival of the Spaniards, the refining of silver. So central was salt to the silver industry that in 1580 the Crown created a royal monopoly over its production and commerce, and while salt mines eventually provided the greatest supply, in the early years of the colony salty lake and spring waters were a key source of that mineral. ${ }^{4}$

The waters of the realm were valued for their "virtues": for their characteristics and efficacy in the world. In 1554, for example, the Crown asked local governments in Mexico to identify "big lakes or notable springs whose waters have some particular virtue" or usefulness due to some essential characteristic of that water. These virtues and their agency were not human, and "virtue" does not refer to the moral principles or forms of reasoning that philosophers in the Western tradition have long debated. Rather, virtues were qualities of the waters identified by their material effects on other bodies, human and nonhuman, and grouped by those effects and their assumed underlying causes. As time passed, the virtues of waters were increasingly defined in terms of therapy and medicine, and the long medical tradition coming down from antiquity through the Arabs identified categories of waters by their effects on human bodies, such as aiding in rheumatism, healing skin disease, or dissolving kidney stones.

While bathing was largely frowned upon during the sixteenth century, its medical applications grew to be accepted by 1600 . A survey questionnaire from 1604, for example, asked that local government officials provide information about "medicinal springs or baths." 5 During the eighteenth century interest in medicinal waters flourished, and the refinement of the categories to describe the variety of those waters is reflected by the 1777 questionnaire, which sought information concerning "hot waters, salty waters, bituminous waters, and those waters useful for certain illnesses, as well as the temperature of the waters and their respective bitterness, bituminous flavor or saltiness."' By 1812 this interest blossomed into an entire field of questions in the census questionnaire (article 11) concerning 
"mineral waters and baths." Respondents were instructed to provide information about the waters themselves, as well as the practices of the people who made use of the waters, and the infrastructure that existed to support the people who visited those waters. ' Underlying this inquiry into the utility of waters was the idea that waters were efficacious, agential, "virtuous."

The changes over time in the questions posed by the government about mineral waters reflect developments in science, medicine, and the business of bathing. Historians suggest that in the eighteenth century intellectuals began to approach waters and their medicinal qualities in a new way. Departing from the Hippocratic and Galenic tradition that was empirical and experimental, scholars working in the emerging scientific paradigm developed a theoretical and systemic approach to understanding the diversity of waters and their particular effects on human organisms and diseases. The results of these investigations into waters and bodies were applied to a growing model of the relations among substances in the universe-chemistry-and scholars distilled, processed, and analyzed the contents of mineral springs to identify their components, locate them in relation to other substances, and discern their effects on the human body. ${ }^{8}$

Mineral springs chemistry had great implications for medicine. Doctors brought new information about the substances in plants and waters to bear on existing schemes for understanding disease and well-being such as temperature, climate, and humors. In 1788 Mexican doctor Juan Manuel Venegas dedicated a section of his Compendio de la Medicina to water treatments, in which he discussed the effects of different temperatures and kinds of waters and different techniques of bathing. The hot mineral waters of Mexico were grouped into categories depending on their principal substance-ferrous, sulfurous, calceous, acidic, and nitrous-each with its applications to particular conditions. He listed dozens of hot springs in New Spain that had already been analyzed for the purpose of promoting medicinal uses. In addition to these hot mineral waters, the doctor described the efficacy of bathing in "common water" for certain conditions, which reveals both the conceptual existence of homogeneous modern water, and that it was at that time simply one kind of water among many. Doctors also elaborated a range of physical applications of waters to bodies-techniques of bathing that corresponded to particular waters or ailments. Half-body baths from the stomach down, or semicupios, were recommended for colic, kidney stone pain, and inflammations in the belly. Foot-baths were prescribed for headaches, facial paralysis, sideaches, and hemorrhoids. Temazcales were useful for sterility in women, paralysis, and "coldness" in the body. These applications were believed to compensate for an excess of some condition in the body (heat, cold, humidity, dryness, viscosity) with an opposing quality (temperature, chemical, area of application) of the water or its application. But while medicine and chemistry developed a new scientific paradigm for understanding waters, their heterogeneity and classificatory order was rooted conceptually in their virtues. 


\section{EXPEDITIONS}

Most of what we know about the development of science occurred in northern and western Europe, and this is especially true of the science of waters. Although less has been written about colonial science, intellectuals in the New World were keenly aware of the latest advances and actively participated in these discussions. ${ }^{9}$ Expeditions mounted in Iberoamerica in the late eighteenth and early nineteenth centuries sought new plants, animals, mines and resources, new routes, and unseen human cultural diversity. Occasionally these expeditions were directed to studying hot springs, and such waters were always mentioned if encountered en route. Colonial space served as a special sort of laboratory, where scientists mounted expeditions to search for the exotic, unusual, and exceptional, and to measure, analyze, and classify these novelties using new methods. The search for the exotic was an older project that lingered on after the paradigm shift to experiment. In 1591, for example, Juan de Cárdenas revealed to readers the "marvelous secrets of the Indies," recounting tales of petrifying waters that caused leaves and other objects to develop a stony, mineral surface. As we shall see, Enlightenment scientists brought new techniques of measurement and description to bear on similarly exceptional natural and human phenomena in the hot springs of New Spain.

Expeditions were controlled by the church and Crown until the early nineteenth century, when imperial power waned and individuals from other countries were granted permission to carry out studies of the Americas. Around 1770 the archbishop of Mexico, Francisco Antonio Lorenzana, sent Fray Pablo de la Purísima Concepción Beaumont to study the hot springs of San Bartolomé, near the city of Querétaro. The springs had been used since at least the 1500 s by locals to relax and feel better, and by the late eighteenth century were managed by the Hippolyte religious order. In 1757 a priest from Querétaro cured his arthritis by bathing in the waters, which spread the fame of the hot springs among the urban elite. With the increasingly popularity of hot springs among bathers, scientists, doctors, and government officials throughout the 17oos, the church sought to develop San Bartolomé hot springs into a hospital and bathhouse. Beaumont had a degree from a university in Paris, and was well acquainted with the "particular treatises" concerning mineral springs in Europe and their curative effects. ${ }^{10}$ His 1772 study of San Bartolomé was the scientific justification for plans to build baths and a hospital for indigenous people and to establish professional medicine at the site.

Beaumont sought to replicate the European model of the spa in rural Mexico. But despite this universal application of medicine and water science, he was well attuned to the specificity of both the springs and their users, for the attractiveness of San Bartolomé resided in its unique virtues. His analysis of the water begins with simple evaluations of its smell and taste: a light sulfur odor and a sharp taste of iron. Reduced by boiling, the water had an effervescent quality, and the solid residues burned readily when put to the flame. Confirming that the distilled water 
was "crystalline" and pure, he continued to process the residual solids with a variety of techniques, deducing finally that the waters were rich in "sulphuric, alkaline, fixed salts." humors" (the alkali) and serve as a sedative and balm for skin disease, respiratory problems, and paralysis (the sulfur). He prescribed the springs for treating arthritis, rheumatism, and gout, and described a set of bathing practices that must be followed. ${ }^{12}$ The patient should take two baths a day of fifteen to thirty minutes, one at $10 \mathrm{a} . \mathrm{m}$. and one at 5 p.m., and after each should be wrapped in clothes to promote profuse sweating. ${ }^{13}$ Drinking the warm water would also induce sweating, which was considered the key to achieving results. For the treatment of renal or pulmonary problems, patients should take semicupios (half-baths) from the waist down. Other maladies required showers-water poured from a considerable height from a bowl. ${ }^{14}$

Beaumont also carried out a social study of the springs and their uses. The waters were used for all purposes by the locals. Of course they bathed in them, but having no other source they also drank only mineral spring water and suffered no obvious deleterious results as far as Beaumont could tell. Once the water left the baths, it irrigated fields of grain and vegetables, also with no negative effects on plants other than fruit trees, which did not grow in the area. The earth around the springs was saturated with minerals, and the Indians use it as a soap they called Xaboxay to wash their clothes in the mineral waters. ${ }^{15}$ The spring itself was fenced off, and the waters were conducted from the source to a large pool through ceramic pipes. Beaumont considered this a wise design, for it prevented the popular practice of cooking chickens and corn in them, or using them to scald and pluck butchered animals. It also conserved the heat, and with it, many of the health benefits of the water. The priest viewed with distrust the practice of local men and women to bathe "one in front of the other, with their unclothed flesh exposed to the four winds", but recognized that because nudity "was almost a custom in these lands" that "maybe there is no spiritual danger." ${ }^{16}$ Nevertheless, "some women who are not Indians take the shameful liberty of bathing in public," a practice Beaumont was eager to put an end to. He suggested that two pools be maintained, so as to separate the sexes and maintain decency and order.

The double standard by which Beaumont evaluates the morality of indigenous and nonindigenous bathers reflects an unresolved tension in Beaumont's treatise between his analysis of the universal benefits of hot springs bathing for humans and his proto-racial theory of the distinctiveness of different groups of bathers. The Indians of the region, he said, "almost lived in the San Bartolomé hot springs, bathing there at all hours of the day and night." ${ }^{17}$ This was natural, he reasoned, for their work in the fields gave them an excess of cold and humidity in their bodies, and the hot springs were the remedy at hand. They "live always naked," which made their skin less delicate and more resistant to the heat of the water. But beyond the cultural differences, Beaumont believed that Indian bodies had a particular physiological 
and chemical composition which responded especially well to these waters. Their bodies, he wrote, were "very oily, their sweat is thick, which is why they do not get gray hair until very old, and, as I have observed in the Real Hospital de Naturales in Mexico, their bones are full of Sulphur." ${ }^{18}$ He maintained that the bones of Indians were "spongy, filled with lots of oily marrow, and sulphurous," which allowed them to bathe at length in the San Bartolomé hot springs and extract great benefits from it. Just as different ailments responded to a water in different ways, so too did different bodies. This understanding of bodily heterogeneity and variable "virtue" jostles alongside Beaumont's framing of the study as an effort to serve a universal "public good" - the health of the population. ${ }^{19}$

This tension between the heterogeneous and homogeneous was at the center of many efforts to understand the world from the emergent scientific perspective in the Enlightenment. Antoine Lavoisier, who identified a number of elements and contributed to the elaboration of the periodic table of elements, was particularly influential among intellectuals in Spain and Mexico. Even before the publication of his major work in 1789 , the idea gained traction that water was a pure substance composed of two hydrogen and one oxygen, and that dissolved into it were other substances that provided all the waters of the world their particular properties. Earlier descriptions of diverse waters based on geography, temperature, astrology, and supernatural forces were replaced with a Linnean array of categories based on the principal impurities found in water: iron, sulfur, carbonate (soda), salt, etc. As Jamie Linton (2010) summarizes it, this was the period during which "waters" became "water," but the creation of the singular did not eradicate the existence of the plural, and hot springs waters continued to be understood in terms of their particular yet variable virtues.

The system of intendancies-regional jurisdictions - that was established in Mexico by the reforming Bourbon government in its Ordenanza of 1786 obliged regional governors to tour their regions and collect scientific information concerning natural history. ${ }^{20}$ This information was expected to help the governors to carry out their duties in the area of Police, and to marshal the resources of the colonies for political and economic development. In March of 1789, the governor of the Intendencia of Valladolid (today Michoacán), Juan Antonio de Riaño, was surveying his territory together with a group of German engineers, in the hope of developing mining resources. While exploring the Jorullo Volcano in Michoacán, they stumbled across a ravine on the flanks of the mountain where there were "various hot springs used as a bath by sick people." ${ }^{21}$ Riaño expressed concern that there were no scientific analyses of the waters, nor doctors to oversee their use by locals. "It turns out," he reported, "that most of the time people bathe in those waters who have diseases that are of such a nature that they do not receive any cure, but rather considerable harm." ${ }^{22}$ He collected samples of the water with the idea that scientific study by colleagues in Mexico City would promote the development of a medical spa business in the Jorullo hot springs. These brief experimental 
forays of institutional science had little effect on local water cultures, and people continued to use hot springs in accordance with their inherited customs. Nevertheless, as we shall see in subsequent chapters, the struggle over ideas and access evidenced in Jorullo defines much of the history of Mexican hot springs from the Enlightenment onward.

With both scientific and economic goals in mind, the Crown financed a series of expeditions in the Americas that collected information about natural resources such as plants, waters, and minerals in order to develop their medicinal uses. Hot mineral springs received special attention because all three of these aspects could be studied at the same: the waters, their mineral content, and the plants that grew around them. At the same time, a series of laical scientific institutions were created in Mexico: the Royal Academy of San Carlos (1781), the Royal Botanical Garden (1788), and the Royal Mining School (1792). The growth and institutionalization of a scientific community of pharmacists and doctors, and the lively discussion of the ideas of Linnaeus and Lavoisier that ensued, helped motivate expeditions to collect samples of plants and mineral waters.

The results of these expeditions, as well as other scientific news, were published in the Gazeta de México, a journal sponsored by King Carlos III and edited by Felipe de Zúñiga y Ontiveros. Upon receiving this commission, de Zúñiga y Ontiveros himself created a questionnaire that was distributed by the viceroy to local officials of New Spain. Among other things, the questionnaire asked for information about "health baths." ${ }^{23}$ Perhaps prompted by this questionnaire, on October 22, 1784, Joséph Ignacio Bartolache and Miguel Fernández of the Real Tribunal del Protomedicato traveled eight miles north of Mexico City to examine the Santa Cecilia springs. After bathing, drinking, and examining the waters they found them to "promote and increase urine, cure indigestions, and dissipate 'hypochondriacal gases."' ${ }^{24}$

The hot springs of the region of Valladolid, what is today Michoacán, were of particular interest to these scientific expeditions. In May 1790 a large group including scientists from Mexico’s Royal Botanical Garden (Real Jardín Botánico), illustrators, servants, and Indians left Mexico City leading a mule train laden down with gear such as compasses, thermometers, glassware, and chemicals. This, the third salida of the Royal Botanical Expedition, had an itinerary that included the provinces of Michoacán and Sonora to the west and north, and the task of recording information about the geography, botany, and other resources of these regions. The group reached the capital of Valladolid (now Morelia) in August and was received warmly by Governor Riaño and the captain of the royal troops, Joséph Bernardo de Fonserrada. As we have seen, Riaño was a naturalist with an interest in analyzing hot spring waters and identifying their medicinal properties and applications. In the morning he escorted the group and their retinue on a field trip to the nearby hot spring of Cuincho, located on a hacienda owned by the Augustine religious order two and a half miles northwest of Valladolid. The group 
inspected the modest bathhouse, with its two rooms, each housing a large tub, and looked over the pipe that brought the hot water from the spring to the bathhouse, as well as another nearby spring that issued cold water. The officials explained the different qualities and uses of the waters to the visiting scientists. ${ }^{25}$

Then the scientists got to work analyzing the waters. They examined the springs, as well as the land and plants around the springs, and took measurements. They water was hot-24 degrees on the Reaumur thermometer (an alcohol-based instrument that divided the range between freezing and boiling into 80 degrees) and it had the weight of distilled water when measured by Beaumés areometer (a hydrometer used for determining the specific gravity of liquids that were lighter than water). They also looked at, touched, tasted, and smelled the water, finding it to be odorless and colorless, with a flavor of acid. To determine the mineral contents of the water the scientists stirred lime (probably $\mathrm{CaO}$ : calcium oxide) into two liters of the water, which resulted in a precipitate of twenty-three grains of carbonic acid, indicating that there was carbon dioxide $\left(\mathrm{CO}_{2}\right)$ mixed into the water $\left(\mathrm{H}_{2} \mathrm{O}\right) .{ }^{26}$ Other reactants produced no precipitates, and so the group extracted the neutral salts by boiling the water and put these aside for analysis back in Mexico City by the director of the Royal Botanical Garden, Vicente Cervantes. They also collected plant specimens around the springs, ordering that information into Linnean categories.

According to the scientists and their guides, the local people frequented the bathhouse to enjoy the "delicias" of the hot water and to treat ailments. This dual function shows that the efforts by church and state discussed in chapters 2 and 3 to reshape bathing as a completely therapeutic, health-oriented practice were not entirely successful. The scientists did not comment on the moral or cultural dimensions of bathing for pleasure, which we have seen in the case of Cuincho to have been recently tinged with sexual scandal involving young women and church officials. Instead, they stuck to their chemistry experiments and had quite a lot to say about the virtues of the waters - their medicinal qualities and therapeutic uses. The locals had gotten it wrong, the scientists wrote, mistaking the accumulations of tequesquite (mostly table salt and bicarbonate of soda) on the walls of the bathhouse for "nitro," a category of explosive nitrogen-based substances. "Everyone lived with the knowledge that there was nitro in the water, which is a very strange substance to be found in mineral waters," they commented. ${ }^{27}$ Under this assumption, and often with the recommendation of a doctor, people bathed in this water with the goal of "tempering the heat in their blood," a condition defined in terms of humoral theories. The scientists declared this faulty analysis and treatment to have led to a failure to cure health problems, and indicated that instead of bathing in it to temper hot blood, people should instead drink it to aid an array of maladies: congested humors, indigestion-producing belches reeking of eggs, "putrid scurvy," and chills.

The chemistry done by these scientists confronted established ideas about the composition of the waters and has been called "the earliest publication found 
yet concerning Lavoisierian chemistry in New Spain," but their understanding of medicine still did not stray far from the climatological and humoral orientation inherited from the Greeks, Romans, and Arabs. ${ }^{28}$ Subsequent studies of mineral springs and their medicinal applications sought more systematic coherence between the modern chemistry employed in testing the waters, and the physiological and chemical understanding of ailments and cures. In 1795 Antonio de Cal, the representative in Puebla for the Royal Botanical Garden and a graduate of its classes on botany, carried out a very similar study of the waters of Tehuacán, which had been used for its therapeutic virtues since the 1600 . And by 1797 , in an article in the Gazeta discussing the hot springs of Xochitepec, the nomenclature of the new science of chemistry was deployed in the analysis of the spring waters, in the diagnosis of the ailments, and in the explanation for the efficacy of the waters and their mineral contents in alleviating the ailments. ${ }^{29}$

The old ontological assumption that waters had "virtues" survived the emergence of chemistry relatively intact and was even strengthened in some ways. The idea that waters were agential, and that this agency could be described in terms of the effects waters had on other bodies, underwrote the idea that waters contained some chemical substance that could be separated out and utilized to treat some similarly chemical problem in the human body. This concept was also at work in the emerging botanical science practiced in the Royal Garden, which was aimed at discovering and utilizing the useful ingredients in plants. The science of waters practiced in Mexico at the end of the eighteenth century thus marks the transition from the experimental, empirical methods of trial and error central to Galenic medicine, to the theoretical and systemic approach ushered in by Lavoisier. This was a fundamentally new way of understanding water as a universal element containing diverse mineral contaminants, as perceived and measured with increasingly precise techniques. But the scientific view subsumed, rather than abolished, the view that waters were multiple and heterogeneous substances whose virtues derived from their environment. Despite the paradigm shift, then, intellectuals did not relinquish the ontological assumption that waters were virtuous.

\section{PEÑÓN DE LOS BAÑOS}

Peñón de los Baños is the name of the small extinct volcanic hill that today lies a few kilometers east of the Zocalo of Mexico City, next to the Benito Juárez international airport. Five hundred years ago, at the moment of contact with Europeans, it was an island in Lake Texcoco, controlled by Aztec emperors and used for hunting. During the colonial period it was an especially important site for the reconfiguration of knowledge about hot springs in New Spain. But more importantly, the history of Peñón in the late eighteenth century reveals how different bathing practices and ontologies of water came together to structure access to the springs. As government reformers and entrepreneurs increasingly set their sights on springs 
during the Bourbon era, hot springs became sites of struggle between customary bathing practices and new businesses, between rich and poor, and between forms of knowledge about waters. A long, simmering conflict emerged between wealthy clients drawn to the new business of leisure bathing that emerged at that time, and the mass of people who had long used the springs for therapeutic ends.

Peñón de los Baños is one of the best-known hot springs in the history of Mexico, but there is no record that its waters were used for bathing before the Spaniards arrived. The island itself was awarded by the Crown to the conquistador Diego de Ordaz in 1539, and by 1554 there was already a "fine vaulted building ... a health bath for sick people" who used the waters despite the general distrust the Spaniards had for bathing at that time. ${ }^{30}$ Among the users was Fray Alonso Urbaño, a Franciscan monk whose use of the baths to cure his crippled feet and hands prompted a visit in June of 1585 from officials of his order who were worried about immorality among their brethren in the New World..$^{31}$ Because his bathing had medical purposes and was backed up with scholarly reasoning (he was described as a "learned and principled" man) he received no sanction. And, as bathing became more accepted by the end of the sixteenth century, the Peñon bathhouse was increasingly frequented by people who were not sick. ${ }^{32}$ Despite popular use for pleasure, members of the Spanish religious and political elite continued to justify bathing in the waters of Peñón principally as a medical practice undergirded by Galenic concepts of health. In 1614 Hernando de Deza, inheritor of the bathhouse and spring, turned the facilities into a trust, the property and proceeds from which to be given over to an orphanage. ${ }^{33}$ De Deza also commanded that the trust pay for a priest to offer mass in the chapel at the bathhouse complex every day, as well as two "black slaves" to shuttle clients back and forth from Mexico City across Lake Texcoco in canoe. These stipulations were not observed by the descendants of de Deza, who abandoned the bathhouse to disrepair amid legal battles over ownership.

In the eighteenth century the practice of bathing in mineral waters became more widespread and extended through newly emerging social groups, and its purposes and justifications diversified. Peñón, abandoned amid legal battles among the heirs of de Deza over ownership, attracted increasing attention by the illustrious, including doctors, scientists, and officials of the government of Mexico City. In 1755 Antonio Villaseñor y Sánchez wrote that "the owners keep it in a state of neglect and great discomfort, even though the usefulness of its waters are wellknown." ${ }^{34}$ The doctor Joséph Dumont, newly arrived to Mexico City in 1740, made his first stop the springs at Peñón de los Baños. Medical and chemical research on mineral springs was flourishing in Europe at that time, and doctors often established their practices in a spa town. Dumont immediately located Peñón as a local curing water source, and influenced by the European example he set to examining the waters of Peñon and prescribing them to his patients.

Many people used the springs to treat their ailments, but this use grew in the mid-eighteenth century, backed by a surge in interest among scientists. In 1752 
Dumont and his colleague Nicolás de Torres were commissioned by the Real Protomedicato to write a study of the waters of Peñon that would explain their "qualities, virtues and uses" with an eye to rehabilitating the abandoned installations for use by a growing bourgeois clientele. They couched the study in religious, biblical terms, a requirement for any scholarly production in a Hispanic world that was deeply skittish about science and secularism in the context of religious conflicts that mapped onto geopolitical struggles in Europe. Dumont argued for the healing properties of mineral waters using references to the Pool of Bethesda (mentioned in the biblical books of Kings and Isaiah, as well as the Gospel of John) which was renowned for its curing properties. He then moved to a scientific discourse, citing secular authors and texts. Following the climatological ideas of Hippocrates's Airs, Waters and Places, he argued that all landscapes produce certain health problems but also provide the elements for their treatment. The humidity of Mexico City, with its lakes and rainfall, caused rheumatism, sciatica, and gout, and God saw fit to provide the waters of Peñón to cure these ailments. Friedrich Hoffman's idea that the body was a hydraulic machine that could be influenced by baths and mineral springs was particularly important to Dumont, but hovered in a strange tension with the mysticism of his biblical references.

Dumont resolved the contradiction between religious and scientific positions by explaining that the healing dynamics of mineral waters on human bodies were designed by God: "[the waters] are a natural pharmacy ... put there by the powerful, wise and liberal hand of the Divine Architect." 35 Reaching beyond previous prescriptions and biblical references to bathing in mineral waters, Dumont followed his colleagues in Europe by proposing drinking the waters. The curing properties of the waters of Peñon were "acclaimed by the People," Dumont states, but he explained how they work by using the science of chemistry, and providing information about how best to use them. For his part, Nicolás de Torres founded his arguments even more explicitly on chemistry, drawing upon Linnean-style classification schemes for mineral waters based on their "active principles," which produce 479,001,070 possible combinations and thus kinds of waters. He also insisted that clients only use the waters under the care of a professional doctor.

Torres and Dumont were part of a government commission charged with developing the facilities at Peñón to receive and treat an expanding clientele of more wealthy citizens, which, under the influence of European ideas and practices, had a newfound interest in hot springs bathing and the money to pay for it. The inheritors of the original bathhouse were embroiled in litigation over who would control the property and the earnings it generated, and this compelled the government to step in. Along with Torres and Dumont, two architects, a judge, and a scribe made up the party that visited the hot springs in 1752 . The facilities had not been renovated since the creation of the De Deza trust in 1614. There was a large bathhouse with three four-room apartments circling a patio, each with a large tub room, and rooms for sleeping. The baths had acquired names and personalities over the 
centuries-Santa Teresa, el Colorado, la Marquesa-but the buildings were a complete shambles, with crumbling roofs and walls and uneven dirt floors. A family had at some point settled in one of these buildings and looked after the installations. The commission found the baths to be worth very little and unlikely to attract customers, both because of the ruinous state of the buildings and because there was no transportation from Mexico City: the canoes and slaves stipulated by the 1614 charter that created the bathhouse trust never materialized. Backed by the Informes of the experts, the royal government forced the transfer of ownership of the bathhouse from the De Deza family to Carlos José Dueñas Pacheco, through the mechanism of an auction that only Dueñas attended. The bathhouse was rebuilt with more space for visitors, and the works were finished in 1765 .

Despite the claims of the government and the businessmen who took over the baths, Peñón did indeed attract visitors in its decrepit state and had done so for centuries. These poor people brought their own concepts of curing and were unlikely to afford the cost of a doctor and a new, renovated bathhouse. They appear only as shadows in the archive, as absent causes of events that do not quite add up. The original pretense of the expropriation and renovation of the bathhouse was that there were no visitors because of the poverty of the installations and the costs of transport. However, in an open letter published in the Gazeta de México in 1794, the new bathhouse operator Andrés Cabellero wrote that one of the stipulations made by the government for the sale of the hot springs in the $1750 \mathrm{~s}$ was the construction of a "bath with its corresponding apartment so that poor invalids with no income could make use of its well-known benefits," a requirement that he gladly fulfilled. ${ }^{36}$ This flow of poor and indigenous patients to Peñon was augmented after the 1764 reopening when, in 1768, the Hospital Real de Naturales contracted to send its indigenous patients daily for treatments. ${ }^{37}$ Caballero was willing, he promised, to open more of the renovated baths to poor people for a quarter of the regular price, if his finances permitted.

There was clearly an established use of the bathhouse among the poor and the indigenous, but the renovation of the bathhouse at Peñon de los Baños was aimed at a new group of relatively wealthy bathers, and in fact the new managers restricted access by poor folks to the resource. In 1791 the city council passed an act prohibiting Peñón's administrator from limiting free access by poor bathers to the bathhouse, or stopping them from taking bottles of water to be used as medicine. ${ }^{38}$ Very few of those who had previously frequented the bathhouse with its dirt floors and collapsing roofs could afford the new two-peso/twenty-four-hour rate, nor were they likely to purchase the pulque, fine wines, and drinking chocolate on sale at the new store. It was unlikely that the administrator had them in mind when he assured the "Public" that all kinds of the most select food was available at the store, "not just the everyday kinds, but also those that the educated and gracious visitor could entertain guests with." 39 The plebe certainly would not make use of the two horse-drawn coaches that brought visitors to Peñón from Mexico City (for two or 
three pesos), nor was it very likely that they would have enough stuff with them to fill the wagon that was for hire. If bathers came on their own horses, and paid to stable them at the bathhouse, they certainly were among the most economically privileged of the public.

The new Peñon bathhouse offered all the comforts that could be found at the spas that were popping up all over Europe to serve the new leisured bourgeoisie: clean rooms, beds, linens, food, drinks, and socialization with peers. After the renovation, "the baths were heavily visited year-round," and the leisured elite came flocking to the site. ${ }^{40}$ In 1777 the archbishop of Puebla, Juan de Viera, recounted that because each apartment had its own bath, "sick people bathe there freely without being registered; usually there are 8-10 families using the bathhouse." ${ }^{41}$ But the medicinal benefits were not the only, or even the principal, attraction for many users, and soon it became a preferred destination for well-to-do urbanites looking to relax in the countryside. According to Viera, "because the bathhouse is so large ... and offers water, greenery, solitude and tranquility, many go there not to bathe but rather to have fun, hunting ducks and rabbits, attending concerts, dances and big banquets that often last two or three days." ${ }^{22}$ In 1793 taxis were shuttling clients to Peñón, and by 1797 a businessman had opened a luxury transport service that carried patients from Mexico City to Peñón in litters. ${ }^{43}$

In keeping with the model of the European spa, Caballero asked doctor Gabriel de Ocampo to publish a scientific, medical statement in conjunction with the announcement of the opening of the renovated bathhouse in the Gazeta de México. Ocampo aimed at "encouraging patients in need to use the waters," offering the bather an analysis of the therapeutic uses of the waters of Peñon based in the quickly evolving sciences of chemistry and medicine and in particular the study carried out on Peñón's waters by the Royal Botanical Expedition in May of $1790 .{ }^{44}$ High temperatures and dissolved gas opened the pores of the skin to allow substances to enter, and the salts, gas, and heat combined to "unblock, relax and dissolve, without taking away the necessary tone of the body's fibers." These properties encouraged the circulation of liquids, unblocked the nervous system, helped with gout and rheumatism, constipation, digestion, and appetite. The exact mixture and proportion of gases, salts, and heat in Peñón's waters was a product of the "sovereign and supreme architect"—God—and could never be replicated in the doctor's office. So only by using the new bathhouse could the "virtues" of the waters be obtained, and only then under the care of "a circumspect and trained doctor." The waters, he warned, could have very negative effects if used improperly. Treatments should be done for ten or more days to gain the "almost miraculous" results, and they could be carried out on people from less than ten years of age to more than eighty.

The unequivocally medical justification for the existence and use of the Peñon bathhouse that is found in Ocampo's letter strikes an uneasy counterpoint with the assurances by Caballero that the bathhouse would provide all the bourgeois 
comforts, and with the descriptions elsewhere of three-day festivities held there in the 1760 s. This is the balance that bathing represented for Mexico's elite since the sixteenth century-of promise and peril, rulers and ruled-only resignified in the Enlightenment discourses of science and citizenship that bubble up in the Spanish empire during the late eighteenth century. Clearly this was a balance that governments in Europe were also negotiating, but in Europe the impact of the bourgeois revolution on water cultures seems to have been steadier, deeper, and more lineal. In Mexico, on the other hand, the emergence of scientific bathing and the policing of water was contested in ways that are not visible in the literature on European spas and hot springs. Humble bathers continued to gain access, one way or another, to the waters, and continued to use them in accordance with ideas and beliefs passed down through generations. And, as we shall see, these long-standing bathing traditions persisted alongside bourgeois involvement in the business and science of bathing in Mexico.

\section{CONCLUSION: THE CONTRADICTIONS OF \\ ENLIGHTENMENT BATHING}

Bathing changed in the eighteenth century. Ideas about health and water rooted in the long tradition of humoral and climatic thought passed down from antiquity through medieval Christian and Arab scholars were reworked by scholars who took a scientific experimental and conceptual approach. Empirical knowledge about the benefits of different waters was systematized according to new categories and classifications generated by chemists. While scholars in Iberia and the Americas continued to frame the study of the physical and natural world in religious terms, this took second place to the descriptions of elements and physical relationships themselves, and how the stuff of the animal, vegetable, and mineral kingdoms influenced wellness and illness in people's bodies. God was given credit as the supreme author or architect of these patterned relationships, but did not much occupy the attention of the new scientists. Nor was religion central to the efforts of government to rule well. The scientific approach to governing was conceived more as a project of managing territories, environments, and populations to ensure order and well-being than in moral terms. Ideas, beliefs, and practices were still central to policing, but increasingly they were disassociated from notions of right and wrong based in spiritual authority. Instead, ideas of civic order and public health guided the proclamations and efforts of government to rationally manage the human relationship to water. More than sin, perhaps, the peril of social bathing was disorder.

The Enlightenment reframing of water culture was rooted in a deep, telluric transformation of economy and society in the eighteenth century that generated new social groups and activities. The growing bourgeoisie in Europe had disposable income and leisure time, and this opened up possibilities for making a 
business of bathing. Spas offered therapy, rural tranquility, and social settings for newly wealthy urbanites. Capital, loosened from moral and political limits of the old order, expanded and flowed toward investment opportunities such as medicine, bathing, and infrastructure development. Although Spain and its colonies participated partially, unevenly, and somewhat belatedly in this historical emergence of capitalism, the Bourbon governments embraced the role of promoting these trends in the water sector by supporting expeditions to study hot springs, and the renovation of bathhouses and urban water systems.

The business of bourgeois bathing was not very successful in New Spain. The Peñón bathhouse was located a few kilometers from the wealthy inhabitants and cosmopolitan tastes of the capital, which made that particular site attractive to some investors. But spa promotors confronted deeply rooted peasant and plebian water cultures based in social and economic principles that were at odds with commoditization. Open access and communal property were prickly obstacles to the enclosure of hot springs, and Peñón's development as a business moved forward only with the concession that at least one bath would remain open to the poor who traditionally used those waters. Hot springs such as San Bartolomé, Topo Chico, or those in Aguascalientes, far from the capital and its emergent bourgeoisie, would remain undeveloped until improved transportation infrastructure enabled spa tourism in the late nineteenth and twentieth centuries (see chapters 7 and 8).

Even with its central location, the bourgeois bathhouse at Peñon soon lost momentum during the War of Independence (1810-21). In 1827, a few years after the wave of nationalist mobilization forced the Spanish Crown to cede control over Mexico and most of its American possessions, José María Manero wrote a letter to the government of the City of Mexico complaining that all the gains made during the rule of Revillagigedo in ordering, rebuilding, and controlling bathing practices at Peñón de los Baños had been lost. The owner of the bathhouse had abandoned his obligations to "repair and maintain the guest rooms, provide all the necessary goods [soap, sponge, towel, etc.]; to keep them clean." ${ }^{45}$

Manero couched his argument in terms of the public need for and benefit from the baths, thus positing the existence of a national citizenry and of public health as a domain of political and economic intervention. What his complaint to the city government did not stress is that people of humble origin had used Peñon's springs and installations before the bourgeois rebuilding, that they succeeded in maintaining some access to it when it was turned into a business, and continued to make use of the facilities when wealthier Mexicans shied away from their decrepit condition. Manero himself saw "many poor sick people" continue to go there to cure their ailments, as did patients under treatment by the hospitals. This use was year-round, and responded to the unpredictable appearance of ailments rather than that of the summer spa season that defined elite bathing in Europe. So in fact much of the "public" was indeed using the bathhouse. But like most of those scholars and officials whose words are recorded in the journals and archives, Manero 
used the universal category of public to reflect the position of a far smaller, elite class of people-the rulers, not the ruled.

Humble folks used the hot springs and bathhouses of Mexico throughout the early nineteenth century, as popular water cultures resumed their ancient courses and the Enlightenment visions of a well-policed bath faded. That project of the bourgeois spa, with its genteel leisure practices and scientific purpose, remained strongly alluring for the elite, however, especially for those who had contact with bathing culture in Europe and the United States. The business of bathing was in latency, awaiting the next cycle of accumulation to mobilize the building of infrastructure, the florescence of concepts, and the policing of practices.

"Like most great ideas of Spanish days, it is now in a state of perfect desolation, though people still flock there for various complaints. When one goes there to bathe, it is necessary to carry a mattress, to lie down on when you leave the bath, linen, a bottle of cold water, of which there is not a drop in the place, and which is particularly necessary for an invalid in case of faintness-in short, everything that you may require. ... We could not help thinking, were these baths in the hands of some enterprising and speculative Yankee, what a fortune he would make; how he would build a hotel a la Saratoga, would paper the rooms, and otherwise beautify this uncouth temple of boiling water."

—Fanny Calderón de la Barca, 1843

Source: Calderón de la Barca 1843: 403-5. 